九州大学学術情報リポジトリ

Kyushu University Institutional Repository

\title{
Application of Wood Vinegars Prepared from Branches and Tree Tops of Cryptomeria japonica at Different Collection Temperatures to Evaluate their Fungi Resistance for Moso Bamboo Material
}

Lin, Han Chien

Department of Forest Products Science, College of Agriculture, National Chiayi University

Fujimoto, Noboru

Laboratory of Wood Material Technology, Division of Biomaterial Science, Department of Forest and Forest Products Sciences, Faculty of Agriculture, Kyushu University

Hwang, Gwo-Shyong

Divisions of Forest Utilization, Taiwan Forestry Research Institute (TFRI)

Wu, She-Ching

Department of Food Science, College of Life Sciences, National Chiayi University

他

https://doi.org/10.5109/16130

出版情報: 九州大学大学院農学研究院紀要. 54 (2)，pp.457-462，2009-10-29. Faculty of Agriculture, Kyushu University

バージョン：

権利関係 : 


\title{
Application of Wood Vinegars Prepared from Branches and Tree Tops of Cryptomeria japonica at Different Collection Temperatures to Evaluate their Fungi Resistance for Moso Bamboo Material
}

\author{
Han Chien LIN ${ }^{1}$, Noboru FUJIMOTO ${ }^{2}$, Gwo-Shyong HWANG ${ }^{3}$, She-Ching WU ${ }^{4 *}$, \\ Chun-Yu LIU ${ }^{5}$, Pei-Ju CHAO ${ }^{5}$, Wei-Ling GUO ${ }^{5}$ \\ and Yi-Tieh SUNG ${ }^{5}$
}

\author{
Laboratory of Wood Material Technology, Division of Biomaterial Science, Department of Forest and \\ Forest Products Sciences, Faculty of Agriculture, Kyushu University, \\ Fukuoka 812-8581, Japanese \\ (Received June 30, 2009 and accepted July 13, 2009)
}

\begin{abstract}
In this study, wood vinegars were collected from the chimney outflow of earthen kiln at 6 different temperatures $\left(80-159,80-90,91-100,101-120,121-140\right.$ and $\left.141-159^{\circ} \mathrm{C}\right)$ during the charcoal preparation from the branches and tree tops of Cryptomeria japonica. These vinegars were used to evaluate the fungi resistance of airborne fungi particles, Aspergillus niger, Aspergillus flavus and Trichoderma viride after they as well as acetic acid and tap water (as the controls) were used to impregnate Moso bamboo specimens for $240 \mathrm{~min}$ using the vacuum method. The basic properties of the wood vinegars obtained were: $\mathrm{pH}$ value of 2.54 to 3.45 , specific gravity ranging from 1.006 to 1.008 , contents of organic acid ranged between 1.75 and $3.03 \%$, soluble tar content was from 0.186 to $0.629 \%$, and the color difference $\left(\Delta \mathrm{E}^{*}\right)$ ranged from 8.37 to 14.36 . The absorption by the bamboo specimens after having been processed with the various vinegars using the vacuum method ranged from 10.85 to $19.35 \mathrm{mg} / \mathrm{cm}^{3}$. The results of the macro-observation showed that after 70 days the growth rate of airborne fungi particle on the surface of bamboo specimens impregnated with vinegar at 80 to $159^{\circ} \mathrm{C}$ range between $10 \%$ and $15 \%$, but it was close to $100 \%$ for either of the controls after only about 30 days. The FTIR analysis showed that the specimens treated with vinegar at 80 to $159{ }^{\circ} \mathrm{C}$ did not contain the fungal chemical compounds, at $1654 \mathrm{~cm}^{-1}(\mathrm{C}=\mathrm{O})$ and $1552 \mathrm{~cm}^{-1}(\mathrm{~N}-\mathrm{H})$, while the acetic acid and the tap water both showed absorbance peaks. The $\mathrm{C} / \mathrm{N}$ ratio of the airborne fungi particles of the specimen treated with vinegar at 80 to $159^{\circ} \mathrm{C}$ was $131.4 \%$, but it was only about 90.5 to $102.8 \%$ for the controls. These results suggest that the compositions of the wood vinegars collected at different temperatures affect the fungi resistance of the bamboo material.
\end{abstract}

Keywords: Wood Vinegar, Branches and Tree Tops Wood of Cryptomeria japonica, Different Collection Temperatures, Fungi Resistance, Moso Bamboo Material

\section{INTRODUCTION}

The Taiwan Forestry Bureau reported that in 2005 forests occupied 2,102,400 hectares (ha), or $59.0 \%$ of the total area $(3,591,500$ ha) of the main island of Taiwan. The natural forest portion measures $1,527,500$ ha or $73.0 \%$ of the forestland. Artificial forests cover another $20.0 \%$, and the others $7 \%$ make up the rest. The majority $(60.0 \%)$ of the natural forests are broad-leaved trees. The majority $(51 \%)$ of the artificial forests are coniferous trees. The total forest volume of the island amounts to about $358,744,000$ cubic meters.

Among these forests, Cryptomeria japonica D.

Department of Forest Products Science, College of Agriculture, National Chiayi University, Chiayi, Taiwan, ROC

${ }^{2}$ Laboratory of Wood Material Technology, Division of Biomaterial Science, Department of Forest and Forest Products Sciences, Faculty of Agriculture, Kyushu University, Japanese

Divisions of Forest Utilization, Taiwan Forestry Research Institute (TFRI), Taipei, Taiwan, ROC

${ }^{4}$ Department of Food Science, College of Life Sciences, National Chiayi University, Chiayi, Taiwan, ROC

${ }^{5}$ Undergraduate Students, Department of Forest Products Science, College of Agriculture, National Chiayi University, Chiayi, Taiwan, ROC

* Corresponding author (E-mail: scwu@mail.ncyu.edu.tw)
Don (Japanese cedar), one of the main plantation species covers 62,500 ha, or about $10 \%$ of the artificial forests. The Japanese cedars are over 30 years old, occupy about 2,300 ha, and have a timber volume of approximately 4 million cubic meters. Plantations need to be thinned, and this is usually done by mechanical means. The results are small-diameter logs (SDLs) and branches and tree tops (BTW)". It is obvious why SDLs and BTW must be removed, such as reducing the forest fire hazard, managing the stand species, obtain a more desirable mix, provide a better wildlife habitat, protect the watersheds, and others (Levan-Green and Livingston, 2001). The SDLs, even low density and high knots material, is utilized for nonstructural lumber, pulp, chips, firewood, paneling (Tsai et al., 1995; Chen et al., 2000; Kim H. G. and Kim K. T., 2000; Hwang, 2003; Lin et al., 2005), biomass energy (Demirbas, 2005; Onay and Kockar, 2003; Stamatov et al., 2006), composting, laminating and so on, but BTW is generally discarded and is under-utilized in Taiwan.

Wood charcoal, a wood product, plays an important role to reduce climate change because it signifies the reduction of carbon in the atmosphere. Therefore, using BTW to make wood charcoal as a valued-added product that accumulates $\mathrm{CO}_{2}$ without spreading it into the atmosphere and at the same time provides jobs for the local 
population is a good deal (Okimori et al., 2003; Ogawa et al., 2006). Wood charcoal made with BTW is a simple way to reduce climate change, even if it no longer absorbs the $\mathrm{CO}_{2}$ from the atmosphere. This is because it directly creates a new way to produce wood charcoal (Hwang et al., 2008), and indirectly plays an important role to increase the efficiency of the forests. However, wood vinegar, a by-product of the wood charcoal manufacturing process using BTW of Cryptomeria japonica, is under-utilized in Taiwan.

Previous studies (Lin et al., 2006a; Lin et al., 2006b; Lin et al., 2008) suggested that bamboo vinegar was useful to restrain molds on bamboo materials and prevented microbiological deterioration. The composition of wood vinegar includes more than 200 kinds of organic compounds, is much more complex than that of bamboo vinegar (Chen et al., 2006; Hwang et al., 2008; Lu and Shau, 2009), and can repel termites and disease germ of plants, improve the soil, promote crop or prevent worm growth, reduce the use of agricultural chemicals, and sterilization (Furuda, 1987; Nishimiya et al., 1998; Yataga, 2002; Ishihara, 2004; Kou, 2005). However, the effect of wood vinegar collected at different temperatures during the production process has never been investigated to determine its fungi resistance on bamboo materials. Therefore, the objective of this study was to evaluate if different collection temperatures of wood vinegars during the manufacturing process of charcoal from BTW of Cryptomeria japonica would influence its fungi resistance, in the hope that it could delete or at least decrease the need for chemical fungicides and their impact on the environment.

\section{MATERIALS AND METHODS}

\section{Specimen preparations}

\section{Bamboo material}

Moso bamboo (Phyllostachys heterocycla Milf) was provided by $\mathrm{Pu}$ Yuan Co. Ltd., Nantou, Taiwan. The specimens were pre-processed by heating at a temperature of 120 to $130{ }^{\circ} \mathrm{C}$ for 1.5 hours. After they were airdried, the specimens, measuring $25 \mathrm{~mm} \times 25 \mathrm{~mm} \times 3 \mathrm{~mm}$ (Length $\times$ Weight $\times$ Thickness) were conditioned to equilibrium at $20^{\circ} \mathrm{C}$ with $65 \%$ relative humidity $(\mathrm{RH})$ for about four weeks. The average moisture content and the density of the specimens was 8.9 to $9.7 \%$ and $0.67(0.01)$ $\mathrm{g} / \mathrm{cm}^{3}$, respectively.

\section{Wood vinegar}

These vinegars, collected at different temperatures during the manufacturing process of charcoal from BTW of Cryptomeria japonica, were provided by the Division of Forest Utilization, Taiwan Forestry Research Institute (TFRI), Taipei, Taiwan (Hwang et al., 2008). The vinegars were collected at temperatures ranging from 80 to $159^{\circ} \mathrm{C}$ (Furuda, 1987; Nishimiya et al., 1998). The temperature was measured by a thermocouple at the chimney outflow of the earthen kiln during the charcoal manufacturing process (pyrolysis) using BTW of Cryptomeria japonica. The different groups of bamboo vinegar were collected at 80-159, 80-90, 91-100, 101-120, 121-140 and

\section{$141-159^{\circ} \mathrm{C}$}

\section{Nutrient media}

Water agar (WA) was used as a nutrient media to maintain/grow the fungi to be used in the tests with either of the specimens in the petri dishes (TAPPI, 1993). WA was purchased from Merck Co, and was prepared using $8 \mathrm{~g}$ of Agar-Agar with $400 \mathrm{~mL}$ of tap water. The preparations were then mixed thoroughly prior to sterilization. Inoculation

The 3 strains of fungi used at an average concentration of suspending liquid of $10^{3-4}$ spore $/ \mathrm{mL}$ were Aspergillus flavus, Aspergillus niger, and Trichoderma viride. In addition, the fungi from air borne spores (airborne fungi particles) were also tested in this study. To obtain the air borne spores the bamboo specimens were exposed to the air in an indoor atmosphere for a period of $10 \mathrm{~min}$.

\section{Experimental methods}

\section{Basic properties}

The experimental tests to determine the $\mathrm{pH}$ value, specific gravity, contents of organic acid and soluble tar content for the various vinegars were the same as in previous studies (Lin et al., 2006b; Lin et al., 2008; Tsai et $a l ., 2009)$. The results of the basic properties were statistically analyzed based on Duncan's multiple range tests at a 5\% significance level using the Statistical Package for Social Science (SPSS) software.

Vacuum treatments

The heated specimens were treated using the vacuum method. The vinegars were kept under a constant pressure of over $600 \mathrm{~mm} / \mathrm{Hg}$. The specimens were then impregnated with each type of wood vinegar, tap water and acetic acid for $60 \mathrm{~min}$ of vacuum time and $240 \mathrm{~min}$ of impregnation time, respectively. The specimens were then individually removed to a drainage pad, tipped on end to allow for drainage and wiped with a paper towel to remove the surface vinegar. They were then weighed to determine the amount of absorption. The absorption formula was the same as in previous studies (Lin et al., 2006b; Lin et al., 2008). The specimens were air dried for $24 \mathrm{~h}$, and then placed into a convection oven at $30{ }^{\circ} \mathrm{C}$ for over $30 \mathrm{~min}$ after which they were cooled and stored in plastic bags for at least 3 days to allow the bamboo vinegar fixation reaction to proceed. They were then reconditioned at $20^{\circ} \mathrm{C}$ with $65 \% \mathrm{RH}$ for 2 weeks. Six replicates of the specimen were prepared for each type of fungus, respectively.

Color value

After the specimens were heat treated and impregnated with the various vinegars, they were each checked using a colorimeter (Nippon Denshoku NR-3000) at 3 randomly selected spots.

Fungi inoculation and fungal resistance

Each fungus was inoculated by distributing 3 drops (about $3 \mathrm{~mL}$ ) onto the surface of the specimen in a petri dish, and then incubating the petri dishes containing the inoculated test-specimens at a temperature of $25^{\circ} \mathrm{C}$ in a humid atmosphere till the growth of each fungus being tested was visible. The fungal resistance experiments 
were determined by visual (macro) examination.

Observation by Microscope

In order to determine the growth of the tested fungi, an inoculated section measuring $5 \mathrm{~mm} \times 5 \mathrm{~mm}$ was taken from each specimen, and then observed using a scanning electron microscope (SEM, HITACH S-2400 types) at 300 $\mathrm{X}$ magnification.

\section{$\mathrm{C} / \mathrm{N}$ ratio measurement}

The oven dried samples weighed about 2-4 mg. Each sample was inoculated individually with one of the various fungi. Each specimen was analyzed after 70 days using an Elemental Vario CHNS/O analyzer (EA, Germany). The $\mathrm{C}$ and $\mathrm{N}$ elements were determined and the $\mathrm{C} / \mathrm{N}$ ratio was calculated.

\section{FTIR analysis}

Seventy days after having been inoculated with the fungi the specimens, each treated with a specific vinegar, were analyzed using the reflectance mode of Fourier Transform Infrared Spectroscopy (FTIR, Perkin Elmer Spectrum RX 1) at a resolution of $4 \mathrm{~cm}^{-1}$. Thirty-two scans were co-added for each spectrum. Infrared transmittance spectra were measured over a range of 650 $4000 \mathrm{~cm}^{-1}$. The peak assignments were performed using the Win FIRST software program.

\section{RESULTS AND DISCUSSION}

\section{Basic properties}

Table 1 shows the basic properties of wood vinegars collected at different temperatures. The $\mathrm{pH}$ value of the vinegars ranged from 2.54 to 3.45, the organic acid content ranged from 1.75 to $3.03 \%$, specific gravity was between 1.006 and 1.008 (between 29.0 and $30{ }^{\circ} \mathrm{C}$ ), and the soluble tar content ranged from 0.186 to $0.629 \%$. The results of the colorimetric measurements of the specimens treated with various wood vinegars are based on the CIE L* a* b* system, and are shown in Table 1 . The color difference $\left(\Delta \mathrm{E}^{*}\right)$ of these specimens was from 8.37 to 14.36 . Their color ranged from light yellow to yellowish-brown, and the $\Delta \mathrm{E}^{*}$ of the treated specimens increased with the increase of the collecting temperature. It is suggested that the color difference is influenced by the soluble tar content and the composition of the various vinegars. The absorption by the heated specimens of wood vinegars from different collection temperatures using the vacuum method ranged from 10.85 to $19.35 \mathrm{mg} / \mathrm{cm}^{3}$. The absorption of tap water was $24.72 \mathrm{mg} /$ $\mathrm{cm}^{3}$ and $13.02 \mathrm{mg} / \mathrm{cm}^{3}$ for acetic acid.

\section{Effect of vinegar collected at different tempera- tures on fungi resistance}

The results of the specimens treated with vinegars collected at different temperatures are shown in Fig. 1. The fungi resistance of the controls, no treatment and treated with acetic acid, was ineffective. It resulted in $100 \%$ fungal colony growth after having been inoculated by various fungi for 5 to 10 days (only the results for specimens inoculated with airborne fungi particles are shown in the top of Fig. 1). The specimens treated with tap water had a fungal colony growth of $82 \%$ after have been inoculated for about 20 days (see the top of Fig. 1). However, after having been treated with a vinegar collected at the respective temperatures, the specimens were fungi resistant to various degrees, as shown in Fig. 1. For the vinegar collected at $80-159^{\circ} \mathrm{C}$, the growth rate of Aspergillus niger was about 15\% 70 days after inoculation. The growth rate was about $8-10 \%$ for airborne fungal particles and for Aspergillus flavus, but 0\% for Trichoderma viride. The growth rate of the specimens treated with vinegar collected at 80-90 and $91-100{ }^{\circ} \mathrm{C} 70$ days after inoculation was about $15-90 \%$ for both Aspergillus flavus and Aspergillus niger, but it was only $0-22 \%$ for both Trichoderma viride and the airborne fungi particles (the left side of Fig. 1). For the specimens treated with vinegar collected at 101-120, 121-140 and $141-159^{\circ} \mathrm{C}$, the growth rate of both Aspergillus flavus and Aspergillus niger was about 20-80\%, but it was only 0 to $15 \%$ for Trichoderma viride and the airborne fungal particles (the right side of Fig. 1) 70 days after inoculation. Moreover, the growth rate of the specimens treated with vinegar collected at 80-159, 91-100, $101-120$ and $121-140{ }^{\circ} \mathrm{C}$ was $0 \%$ for both Trichoderma viride and the airborne fungi particles, 70 days after inoculation. These findings indicate

Table 1. Basic properties of wood vinegars prepared from branches and tree tops wood of Cryptomeria japonica with the different collected temperatures

\begin{tabular}{|c|c|c|c|c|c|c|}
\hline \multirow{2}{*}{$\begin{array}{l}\text { Bamboo vinegar } \\
\left({ }^{\circ} \mathrm{C}\right)\end{array}$} & \multirow{2}{*}{$\mathrm{pH}$ value } & \multirow{2}{*}{$\begin{array}{l}\text { Organic acid content } \\
\text { (\%) }\end{array}$} & \multicolumn{2}{|c|}{ Specific gravity tests } & \multirow{2}{*}{$\begin{array}{l}\text { Soluble tar content } \\
\text { (\%) }\end{array}$} & \multirow{2}{*}{$\Delta \mathrm{E}^{* 2)}$} \\
\hline & & & Temperature $\left({ }^{\circ} \mathrm{C}\right)$ & $\mathrm{SG}^{1)}$ & & \\
\hline $80-159$ & 2.59 & $2.81(0.06)^{\text {а3) }}$ & 29.5 & 1.007 & $0.389(0.01)^{a}$ & $11.31(0.12)^{\mathrm{a}}$ \\
\hline $80-90$ & 2.54 & $1.90(0.09)^{c}$ & 29.5 & 1.006 & $0.186(0.00)^{d}$ & $8.37(0.31)^{d}$ \\
\hline $91-100$ & 2.55 & $3.03(0.16)^{a}$ & 29.0 & 1.008 & $0.566(0.02)^{b}$ & $11.97(0.06)^{\mathrm{a}}$ \\
\hline $101-120$ & 2.80 & $1.75(0.08)^{c}$ & 29.5 & 1.007 & $0.409(0.05)^{a}$ & $10.04(0.44)^{b}$ \\
\hline $121-140$ & 2.79 & $2.65(0.06)^{a}$ & 29.0 & 1.007 & $0.629(0.04)^{\mathrm{c}}$ & $14.36(0.30)^{c}$ \\
\hline $141-159$ & 3.45 & $2.03(0.12)^{\mathrm{b}}$ & 30.0 & 1.008 & $0.615(0.04)^{\mathrm{c}}$ & $13.25(0.39)^{\mathrm{c}}$ \\
\hline
\end{tabular}

1) SG: Specific Gravity.

2) $\Delta \mathrm{E}^{*}=\left(\Delta \mathrm{L}^{* 2}+\Delta \mathrm{a}^{*^{2}}+\Delta \mathrm{b}^{* 2}\right)^{1 / 2}$ : Color difference.

3) Mean (standard deviation) separation within columns by Duncan's multiple range tests at $5 \%$ significant level. 


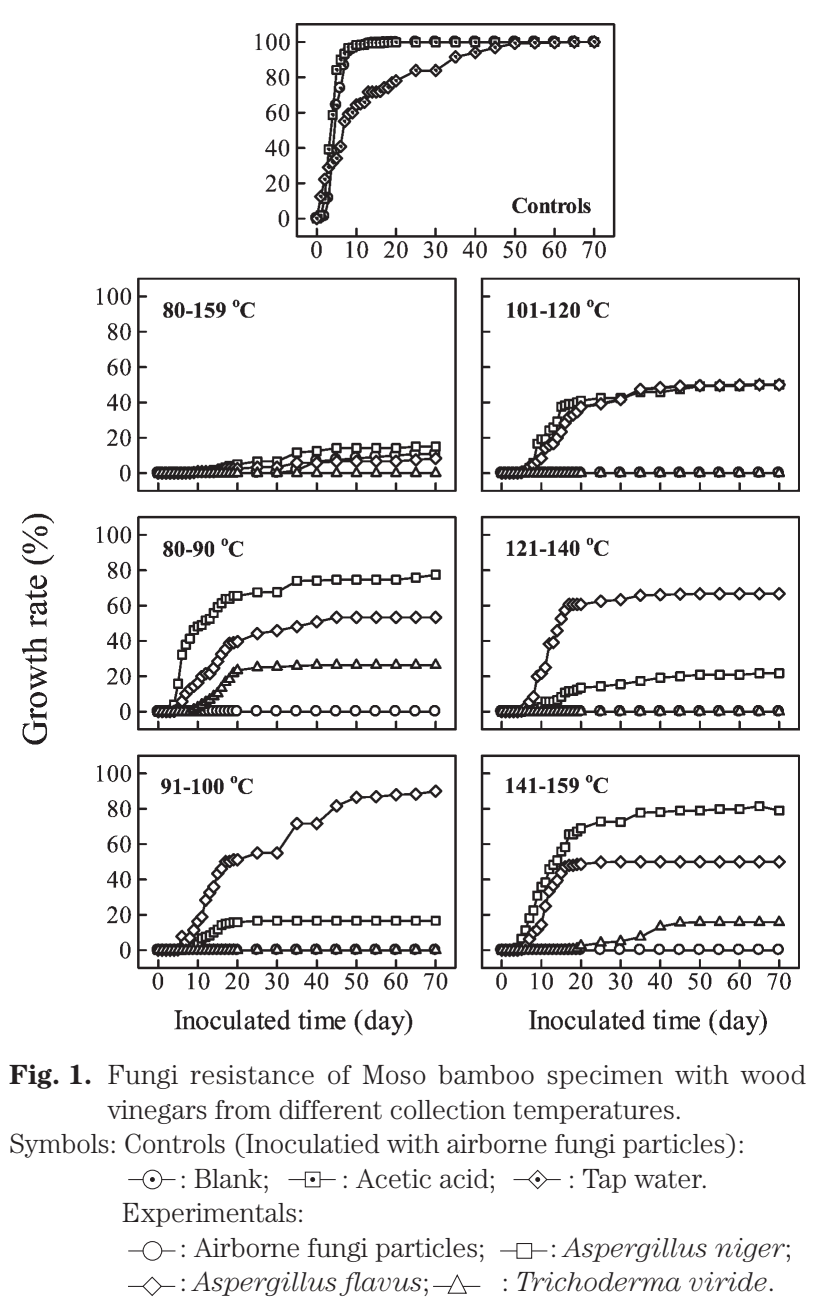

that wood vinegars collected at different temperatures can restrain molds and decrease the microbiological deterioration of products made with bamboo. It also indicates that the temperature of the wood vinegar at the time of collection influences the effectiveness of the fungi resistance of the treated bamboo materials. This study suggests that it is critical for future research to investigate which of the organic compounds in the wood vinegars prepared from the BTW of Cryptomeria japonica are the main fungicides, and which are the most effective collection temperatures.

A micrograph by scanning electron microscope (SEM) for the resistance to fungi of specimens treated with vinegar collected at a temperature of $80-159^{\circ} \mathrm{C}$ is shown in Fig. 2. The 300 times SEM micrograph of the side view of the specimens 70 days after having been inoculated with airborne fungi particles, indicates that there was only a small fungal colony growth for both the airborne fungi particles (top figure - left side of Fig. 2) and for Trichoderma viride (bottom figure - right side of Fig. 2). However, for the specimens with both Aspergillus flavus and Aspergillus niger, it showed a substantial amount of fungal strains on the side of the specimens.

The $\mathrm{C} / \mathrm{N}$ ratios of the control specimens, treated with both tap water and acetic acid, were lower than those of the specimens treated with wood vinegars at different

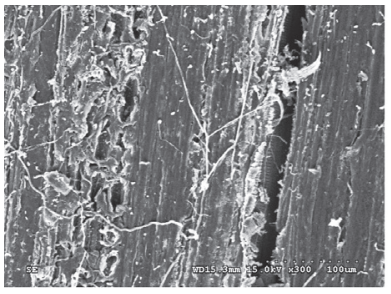

Airborne fungi particles

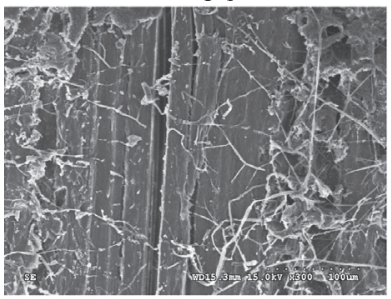

Aspergillus flavus

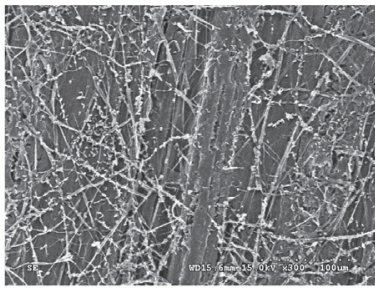

Aspergillus niger

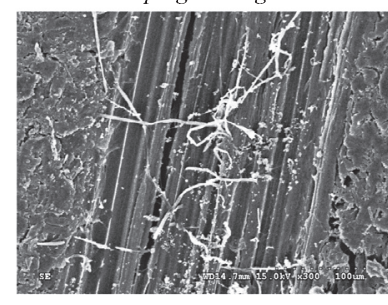

Trichoderma viride
Fig. 2. SEM photographs $(\times 300)$ of various fungi at inoculated side for Moso bamboo specimen treating with $80-159{ }^{\circ} \mathrm{C}$ of wood vinegar by using vacuum treatment after 70 days.

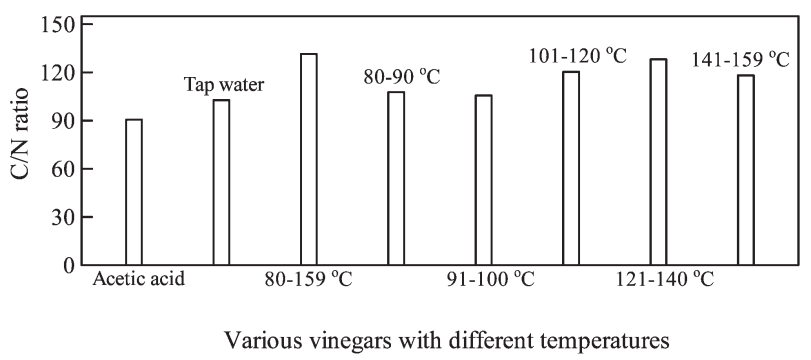

Fig. 3. $\mathrm{C} / \mathrm{N}$ ratio for bamboo specimen treating with different collected temperatures of wood vinegars after inoculated airborne fungi particles for 70 days.

temperatures after having been inoculated by airborne fungal particles for 70 days (Fig. 3). This is because the amino acids of the inoculated fungi increased as a result of their metabolism of fungal microorganism (Fujida, 1993; Rayner and Boddy, 1988; Fukuda, 2000; Lin, 2003). In other words, the $\mathrm{N}$ element increased. It is confirmed that the lower the $\mathrm{C} / \mathrm{N}$ ratio, the greater the rate of biodegradation (Lin et al., 2006a; Lin et al., 2006b; Lin et al., 2008).

\section{FTIR analysis}

To understand the effectiveness of the resistance to fungus of the specimens treated with vinegars collected at various temperatures and the controls (no treatment, acetic acid and tap water), the specimens inoculated with various fungi were examined using FTIR analysis. One of the results for the specimens inoculated with Aspergillus niger are shown in Fig. 4.

The results of the FTIR spectra for these specimens after 70 days showed that for the controls, two absorbance peaks located at $1654 \mathrm{~cm}^{-1}$ and $1552 \mathrm{~cm}^{-1}$, were assigned to $\mathrm{C}=\mathrm{O}$ (carbonyl group) stretching and $\mathrm{N}-\mathrm{H}$ deformation vibration, respectively. And the weaker peaks for both functional groups also showed on the specimens treated with vinegars collected at 80-90, 91-100, 


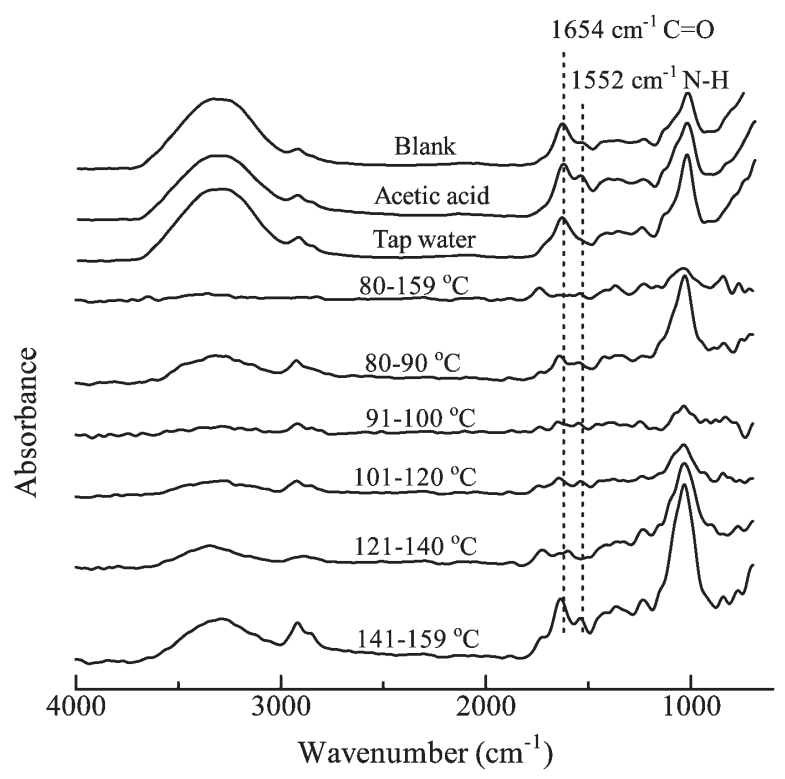

Fig. 4. FTIR spectra of bamboo specimens treating with different collected temperatures of wood vinegars by using vacuum treatment after inoculated Aspergillus niger for 70 days.

Note: The controls are included Blank, Acetic acid and Tap water.

101-120 and $141-159^{\circ} \mathrm{C}$. However, neither peak was present for the specimens with vinegars at 80-159 and $121-140{ }^{\circ} \mathrm{C}$. These results are similar to the results of the resistance of bamboo specimen to Aspergillus niger when treated with wood vinegars collected at different temperatures (see Fig.1). In other words, it seems that both peaks, $1654 \mathrm{~cm}^{-1}(\mathrm{C}=\mathrm{O})$ and $1552 \mathrm{~cm}^{-1}(\mathrm{~N}-\mathrm{H})$, represented the chemical compounds of the representative function group, as indicated by the fungi on the bamboo surface. This is because the main compounds of the cell wall of the fungi are made up of chitin, cellulose, aminosaccharides, protein, etc. As such $\mathrm{C}=\mathrm{O}$ can be a representative for their function group (Chang, 1990). For the function group N-H, it could be the amino acid products that were increased through the metabolization of fungal microorganisms (Lin, 2003; Lin et al., 2006). Therefore, it can be concluded that wood vinegars collected at different temperatures are useful for restraining molds by treating the bamboo product by the vacuum method, applying $60 \mathrm{~min}$ of vacuum and $240 \mathrm{~min}$ of impregnation.

\section{CONCLUSIONS}

This study used wood vinegar prepared from BTW of Cryptomeria japonica and collected at different temperatures to evaluate the fungi resistance of Moso bamboo material when treated with these wood vinegars. The results obtained are summarized as follows. The $\mathrm{pH}$ value, specific gravity, contents of organic acid, soluble tar content and color difference of wood vinegars were 2.54 to $3.45,1.006$ to $1.008,1.75$ to $3.03 \%, 0.186$ to $0.629 \%$ and 8.37 to 14.36 , respectively. The absorption with each wood vinegar by the bamboo specimens using the vacuum method was about 10.85 to $19.35 \mathrm{mg} / \mathrm{cm}^{3}$.
Seventy days after the surface of the bamboo specimens were inoculated with vinegars at 80 to $159^{\circ} \mathrm{C}$ the growth rate of the airborne fungi particles was only about 10 to $15 \%$ of that of the other specimens. At the same time, the growth rate for both controls was close to $100 \%$ after only 30 days. It is evident that wood vinegars collected at different temperatures can restrain bamboo molds and reduce the microbiological deterioration of bamboo products. The $\mathrm{C} / \mathrm{N}$ ratio of the specimen inoculated with airborne fungus particles and treated with vinegar collected at 80 to $159^{\circ} \mathrm{C}$ was $131.4 \%$, and about 90.5 to $102.8 \%$ for the controls. The FTIR analysis showed that the specimens treated with vinegars collected at temperatures from 80 to $159^{\circ} \mathrm{C}$ were found not to be the functional groups of the fungal chemical compounds, at $1654 \mathrm{~cm}^{-1}(\mathrm{C}=\mathrm{O})$ and $1552 \mathrm{~cm}^{-1}(\mathrm{~N}-\mathrm{H})$. It is evident from the results of the $\mathrm{C} / \mathrm{N}$ ratio and the FTIR analysis, that wood vinegar can reduce the microbiological deterioration in bamboo materials.

\section{ACKNOWLEDGEMENTS}

The authors are grateful to the Pu Yuan Co. Ltd., Nantou, Taiwan, for providing the bamboo materials for our experiment, and to Dr. Tsang-Chyi Shiah for offering the suspending liquid of fungi strains.

\section{REFERENCES}

Chang, S. T. 1990 Chemical Characterization of Woody Materials and Coatings Using Fourier Transform Infrared Microspectroscopy. Quarterly Journal of Chinese Forestry, 23(1): 87-103

Chen, T. Y., M. R. Hsu, H. C. Chen, C. H. Hsu 2000 Study on Densification of Wood Surface Layers. Forest Products Industries, 22(4): 1-12

Chen, C. H, K. T. Lu, L. W. Hung, C. T. Liu and C. H. Yen 2006 Manufacture of Wood Charcoals and Wood Vinegars from Floating Wood and Their Utilization on the Culture of Plants (I) Manufacture of Wood Charcoals and Wood Vinegars from Floating Softwood. Quarterly Journal of Forest Research, $\mathbf{2 8}(4)$ : $87-98$

Demirbas, A. 2005 Pyrolysis of Ground Beech Wood in Irregular Heating Rate conditions. J. Anal. Appl. Pyrolysis, $\mathbf{7 3}$ 39-43

Fujida, K. 1993 Composite Technology. Gihoutou Publication, pp. $69-70$

Fukuda, K. 2000 Deterioration and Increasing Durability of Thatched Roof. Data of Wood Research, 16: 1-16

Hwang, G. S. 2003 Compression Set of China-fir Transversely Compressed Wood. Forest Products Industries, 22(2): 99-106

Hwang, G. S., Y. J. Lin, C. L. Ho and H. Y. Yu 2008 Study on Charcoal Marking with Branches and Tops Wood of Cryptomeria japonica Using an Earthen Kiln. Abstracts of The 2008 Annual meeting of The Chinese Forest Products Association, pp. 27-33

Ishihara, S. 1996 Development of Wood-based Charcoal Materials, Mokuzaigakkaishi, 42(8): 717-723

Kim, H. G. and K. T. Kim 2000 Densification behavior of Tungsten-Fiber-Reinforced Copper Powder Compacts under Hot Isostatic Pressing. International J. of Mechanical Sciences, 42: 1339-1356

Kou, C. W. 2004 Effects of Heating Rates on Fundamental Properties of Vinegar during Bamboo Carbonization and Its Application on Inhibit Plant Pathogenic Bacteria, Master thesis of National Chung University, Total pages 76 
Levan-Green, S. L., J. Livingston 2001 Exploring the Uses for Small-Diameter Trees. Forest Product J., 51(9): 10-21

Lin, J. C. 2003 Investigation and Analysis on Weather Degradation of Wood Construction Materials for Traditional Taiwanese Architectures. Ph. D Dissertation, pp. 144-157

Lin, H. C., T. Ohuchi, Y. Murase and T. C. Shiah 2005 Manufacturing Flame-Retardant Panels from Japanese Cedar by the Pressure Process Combined with Hot Pressing Techniques. J. of the Faculty of Agriculture Kyushu University. Japan, 50(2): 327-341

Lin, H. C., T. Ohuchi, Y. Murase, T. C. Shiah, S. L. Shieh, P. C. Chiu, Y. M. Juan and S. C. Cheng 2006a Application of Bamboo Vinegar with Vacuum Process to Evaluate Fungi Resistance of Bamboo Materials. Journal of the Faculty of Agriculture Kyushu University. Japan, 51(1): 5-11

Lin, H. C. and T. C. Shiah 2006b Evaluation of Fungi Resistance of Moso Bamboo Materials Using Bamboo Vinegar with Smoking Process. Quart. Journal Forest Research of Taiwan. Taiwan ROC, $\mathbf{2 8}(2)$ : 51-66

Lin, H. C., Y. Murase, T. C. Shiah, G. S. Hwang, P. K. Chen and W. L. Wu 2008 Application of Moso Bamboo Vinegar with Different Collection Temperatures to Evaluate Fungi Resistance of Moso Bamboo Materials. Journal of the Faculty of Agriculture Kyushu University. Japan, 53(1): $107-113$

Nishimiya, K., T. Hata, Y. Imamura and S. Ishihara 1998 Analysis of Chemical Structure of Wood Charcoal by X-ray Photoelectron Spectroscopy. J. Wood Sci., 44: 56-61

Ogawa, M., Y. Okimori and F. Takahashi 2006 Carbon Sequestration by Carbonization of Biomass and Forestation:
Three Case Studies. J. Mitigation and Adaptation Strategies for Global Change, 11(2): 421-436

Okimori, Y., M. Ogawa and F. Takahashi 2006 Potential of $\mathrm{CO}_{2}$ Emission Reductions by Carbonizing Biomass waste from Industrial Tree Plantation in South Sumatra, Indonesea: Three Case Studies. J. Mitigation and Adaptation Strategies for Global Change, 8(3): 261-280

Onay, O. and O. M. Kockar 2003 Slow, Fast and Flash Pyrolysis of Rapeseed. Renewable Energy, 28: 2417-2413

Rayner, A. D. M., L. Boddy 1988 Fungal decomposition of WoodIts Biology and Ecology. A Wiley-Interscience Publication, Chichester, New York, Brisbane, Toronto, Singapore, pp. 38-46

Stamatov, V., D. Honnery and J. Soria 2006 Combustion Properties of Slow Pyrolysis Bio-oil Produced from Indigenous Australian Species, Renewable Energy, 31: 2108-2121

Tsai, C. T., S. C. Wu, K. J. Lin, G. S. Hwang and H. C. Lin 2009 Evaluation of Antioxidation Activity and Resist Lipid Oxidation Effect with Moso Bamboo Vinegar Collection From Different Temperature. J. Agric For. (NCYU), 6(1): 66-83

The Taiwan Forestry Bureau 2005 The forested lands in Taiwan Island proper. Taiwan Forestry Bureau

Tsai, W. C., S. Y. Wang, C. M. Tsai 1995 Effect of Board Thickness, Fire-Retardant Retention and Degradation of Fire-Retardant Chemical on the Toxicity of Combustion Gas Forest Products Industries, 20(2): 153-164

Yataga, M. M. Nishimoto, K. Hori, T. Ohira and A. Shibata 2002 Termiticidal Activity of Wood vinegar, It's Components and Their Homologues. J. Wood Sci, 48: 338-342 